\title{
Peningkatan Kompetensi Guru Melalui Pelatihan Media Pembelajaran Interaktif Berbasis Videoscribe bagi Guru MGMP Fisika Kabupaten Lebak
}

\author{
Indica Yona Okyranida ${ }^{1}$, Irnin Agustina Dwi Astuti ${ }^{2}$ \\ 1,2 Universitas Indraprasta PGRI, Indonesia
}

\begin{abstract}
A B S T R A C T
IMPROVING TEACHER COMPETENCE THROUGH TRAINING ON VIDEOSCRIBE-BASED INTERACTIVE LEARNING MEDIA FOR TEACHERS OF PHYSICS MGMP IN LEBAK REGENCY. The purpose of this community service is to increase the role of MGMP physics teacher in Lebak District in developing interactive learning media innovation. Media Innovation learning the form of learning media based Videoscribe. The weakness of teachers in making media learning makes a problem to be sought solution. One of the developments in science and technology that can be utilized as an effective and efficient learning media in physics learning is by making interactive learning media based Videoscribe. The method of public service is conducted by interview, observation, socialization, and training. Community service activities in the MGMP Physics district Lebak goes well according to the results of the questionnaire feedback the level of satisfaction of partners in the implementation of devotion to the community who said that partners respond to positive response (95\%) With this devotion activity. This activity adds teachers' skills to create an interactive and innovative learning medium for preparing teaching materials in schools. Media-based Videoscribe learning is one of the latest innovations for teachers in the MGMP Physics of Lebak district.

Keywords: Learning Media, Physics Learning, Videoscribe.

\begin{tabular}{llll}
\hline Received: & Revised: & Accepted: & Available online: \\
21.01 .2020 & 19.05 .2020 & 16.10 .2020 & 30.11 .2020 \\
\hline
\end{tabular}
\end{abstract}

\section{Suggested citation:}

Okyranida, I. Y., \& Astuti, I. A. D. (2020). Peningkatan kompetensi guru melalui pelatihan media pembelajaran interaktif berbasis videoscribe bagi guru MGMP fisika Kabupaten Lebak. Jurnal Pengabdian Pada Masyarakat, 5(4), 1035-1042. https://doi.org/10.30653/002.202054.406

Open Access I URL: http://ppm.ejournal.id/index.php/pengabdian/article/view/406

\footnotetext{
${ }^{1}$ Corresponding Author: Universitas Indraprasta PGRI; TB. Simatupang, Jl. Nangka Raya No. 58 C, RT.5 RW.5, Tj. Bar., Kec. Jagakarsa, Kota Jakarta Selatan, Daerah Khusus Ibukota Jakarta 12530, Indonesia. Email: indicaoky@gmail.com
} 


\section{PENDAHULUAN}

Pada zaman modern seperti sekarang ini, kemajuan teknologi di bidang informasi dan komunikasi terus meningkat. Saat ini semua orang dapat memperoleh segala informasi hanya dengan mengakses internet. Terlebih lagi, perkembangan internet diimbangi dengan perkembangan perangkat keras atau pun perangkat lunak serta banyak nya aplikasi yang bertujuan untuk memudahkan pekerjaan sehari-hari baik di bidang pendidikan, perkantoran, dan lainnya (Pariartha, Parmiti, \& Sudatha, 2013).

Di bidang pendidikan, media internet sering kali digunakan sebagai media pembelajaran yakni alat bantu untuk memperagakan fakta, konsep, prinsip atau prosedur tertentu agar tampak lebih nyata atau konkrit (Dasmo, Astuti, \& Sumarni, 2017). Hal ini bertujuan untuk memberikan pengalaman lebih konkrit, memotivasi serta meningkatkan daya serap dan daya ingat siswa dalam balajar.

Berdasarkan wawancara dengan beberapa beberapa guru fisika di Kabupaten Lebak, mayoritas guru fisika jarang menggunakan media pembelajaran berbasis teknologi. Hal tersebut dikarenakan guru malas untuk membuat media pembelajaran dan kurangnya skill dalam membuat media pembelajaran. Sebagian guru mengajar fisika hanya menggunakan media powerpoint ataupun bahan ajar buku. Hal tersebut membuat sebagian besar siswa merasa bosan dan jenuh ketika belajar fisika di kelas. Sarana dan prasarana yang terdapat di sekolah sebenarnya bisa digunakan untuk mendukung dalam proses pembelajaran, tetapi kurang dimanfaatkan dengan baik.

Pelajaran di sekolah harus didesain sedemikian rupa melalui media pembelajaran agar siswa dapat lebih tertarik dalam belajar di dalam kelas. Kegiatan belajar mengajar sebaiknya dilakukan dengan menghadirkan media pembelajaran yang dapat memvisualisasikan konsep pelajaran yang masih abstrak.

Komputer erat kaitannya dengan dunia pendidikan. Bahkan komputer telah menjadi mata pelajaran wajib di sekolah-sekolah. Banyak pekerjaan di dunia pendidikan yang dapat dibantu pekerjaannya oleh komputer. Mengetik, berhitung, mencari materi pelajaran dari internet, dan pekerjaan lainnya, telah menjadi menu rutin komputer di sekolah-sekolah. Dalam bidang pengajaran, komputer memungkinkan untuk terselenggaranya proses belajar mengajar jarak jauh, atau pembelajaran tanpa tatap muka. Namun demikian masalah yang timbul tidak semudah yang dibayangkan. Pengajar dalam hal ini, guru yang menguasai materi pelajaran, sebagian besar tidak mampu menghadirkan bentuk pembelajaran dalam komputer, sedangkan ahli komputer yang mampu merealisasikan segala hal dalam komputer biasanya tidak menguasai materi pelajaran (Ena, 2001).

Dalam membuat atau menetapkan media perlu memperhatikan kriteria pemilihan media. Arsyad (2009) menyampaikan kriteria yang harus diperhatikan diantaranya adalah kesesuaian dengan tujuan yang ingin dicapai, mendukung isi pelajaran, praktis, luwes dan bertahan, keterampilan guru dalam menggunakan, pengelompokkan sasaran, serta mutu teknis. Sedangkan Winastiti, Kurniawan, dan Maftukhin (2012, p. 28) menjelaskan beberapa faktor dan kriteria yang harus diperhatikan yaitu obyektifitas, kesesuaian program pengajaran, sasaran program, situasi dan kondisi, serta kualitas teknis.

Salah satu perkembangan ilmu pengetahuan dan teknologi yang dapat dimanfaatkan sebagai media belajar yang efektif dan efisien dalam pembelajaran yaitu 
dengan membuat media pembelajaran interaktif engan menggunakan videoscribe. Media audio visual dengan menggunakan Videoscribe untuk penyajian informasi serta meningkatkan efektifitas pembelajaran (Octavianingrum, 2016). Video scribe dapat mengilustrasikan konsep yang kompleks dalam pembelajaan, meningkatkan minat, dan motivasi siswa (Sparkol, 2014).

Videoscribe merupakan sebuah software yang digunakan guru dan siswa membuat animasi berbentuk papan tulis untuk meningkatkan minat dan retensi dalam pembelajaran. Videoscribe memiliki kelebihan karena videoscribe merupakan aplikasi online dan bernuansa multimedia serta dapat berupa foto, gambar, teks, musik, dan background yang dapat dipilih sesuai keinginan (Octavianingrum, 2016). Dengan berbagai karakter yang terdapat dalam videoscribe ummumnya mampu meningkatkan proses pembelaaran lebih hidup lagi dan tidak monoton, sebab pembelajaran lebih bervariasi. Videoscribe dapat meningkatkan pembelajaran dengan mengkombinasikan audio dan visual. Menurut Rahmawati (2012) siswa lebih memahami konsep dalam pembelajaran dengan animasi. Kunci untuk keberhasilan pendidikan sains adalah penggunaan alat teknologi yang bisa meningkatkan pemahaman konsep sains siswa (Isman, Yaratan, \& Caner, 2007).

Berdasarkan masalah tersebut, tim abdimas akan melaksanakan kegiatan pengabdian kepada masyarakat di MGMP Fisika Kabupaten Lebak dalam kegiatan pelatihan pembuatan media pembelajaran interaktif berbasis videoscribe.

\section{METODE}

Kegiatan pengabdian kepada masyarakat ini telah dilaksanakan di MGMP Fisika Kabupaten Lebak yang berpusat di SMA Negeri 1 Rangkasbitung, Kabupaten Lebak, Banten. Kegiatan ini dilaksanakan pada bulan Oktober 2019 sampai dengan Januari 2020. Bahan yang digunakan dalam kegiatan ini adalah laptop, modul media pembelajaran berbasis videoscribe, dan LCD proyektor.

Metode yang digunakan dalam kegiatan pengabdian kepada masyarakat ini adalah metode pelatihan, diskusi, dan pendampingan. Pelatihan dilakukan dengan cara memberikan pelatihan seputar konsep, dan penggunaan PhET simulation dalam pembelajaran.

Pelaksanaan kegiatan ini dilakukan dalam tiga tahapan yaitu tahap persiapan, pelaksanaan, dan evaluasi yang dijabarkan sebagai berikut.

1) Tahap persiapan. Pada tahap persiapan, tim abdimas melakukan survei pendahuluan untuk menganalisis lokasi mitra, kebutuhan pelatihan yang dibutuhkan mitra, dan menyusun rancangan kegiatan yang akan dilakukan, serta menyusun instrumen.

2) Tahap pelaksanaan. Pada tahap ini, tim abdimas, melakukan pelatihan media pembelajaran berbasis videoscribe yang ditujukan kepada seluruh guru fisika SMA yang tergabung dalam MGMP Fisika Kabupaten Lebak, Banten. Kegiatan ini dilakukan dengan tujuan agar guru dapat meningkatkan kompetensinya melalui ini..

3) Tahap evaluasi. Pada tahap ini, tim abdimas melakukan evaluasi terhadap proses kegiatan. Evaluasi dilakukan dimulai dari pra pelaksanaan yang meliputi analisis 
kebutuhan mitra, kehadiran peserta pelatihan, respon serta saran terhadap kegiatan. kegiatan abdimas ini terlihat pada gambar 1.

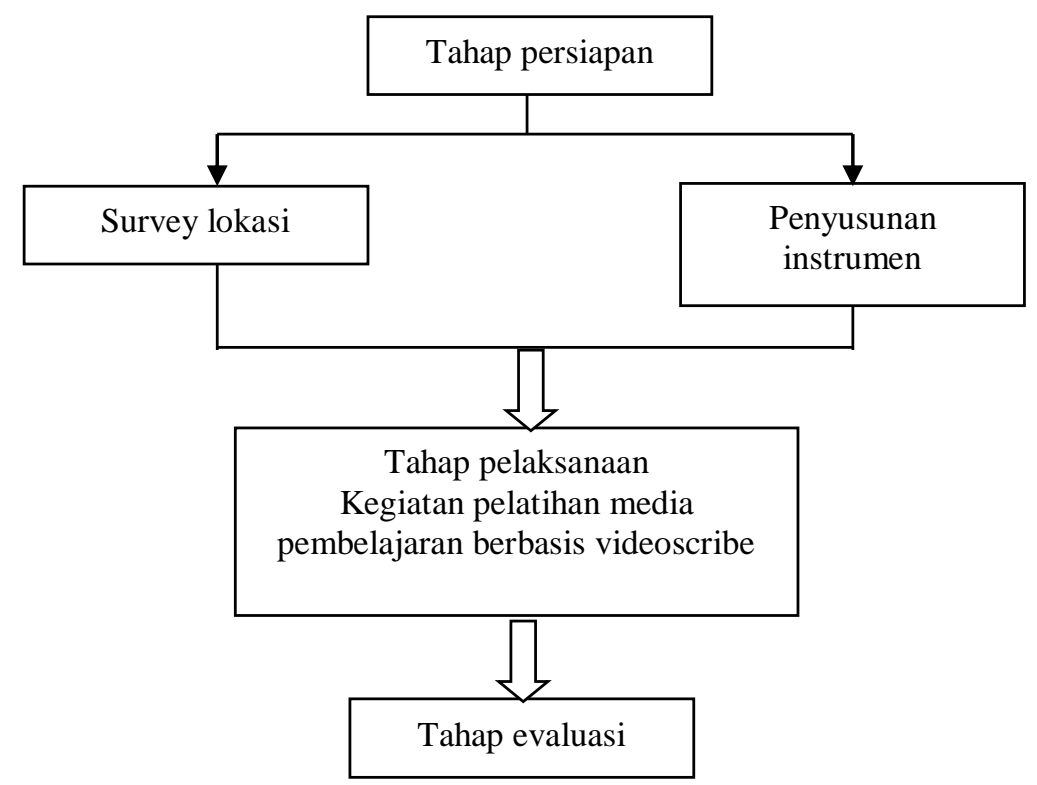

Gambar 1. Diagram Alur Kegatan Pengabdian kepada Masyarakat

\section{HASIL DAN PEMBAHASAN}

Program pengabdian kepada masyarakat ini telah dilaksanakan di MGMP fisika Kabupaten Lebak, yang berpusat di SMA N 1 Rangkasbitung. Realisasi kegiatan ini dilakukan dalam tiga tahap, yakni tahap persiapan, pelaksanaan dan evaluasi. Tahap pertama adalah tahap persiapan. Pada tahap ini tim melakukan survei pendahuluan bulan Agustus 2019 untuk mengetahui kondisi pada mitra dengan menganalisis kondisi tempat yang akan digunakan, kondisi peserta yang akan diberikan perlakuan (guru fisika yang tergabung dalam MGMP Fisika Kabupaten Lebak, Banten) dan menyusun rancangan kegiatan yang akan dilakukan. Tahap persiapan selanjutnya, tim menyiapkan bahan presentasi, modul media pembelajaran berbasis videoscribe, sarana dan prasarana untuk melengkapi kegiatan pelatihan seperti laptop dan LCD proyektor untuk pemaparan materi.

Tahap selanjutnya adalah tahap pelaksanaan. Pada tahap ini tim melakukan pelatihan pembuatan media pembelajaran interaktif berbasis videoscribe. Pelatihan dilaksanakan selama 1 hari yakni tanggal 17 Januari 2020. Pelatihan dihadiri 36 orang guru fisika yang tergabung dalam MGMP Fisika Kabupaten Lebak, Banten. Kegiatan dilakukan dengan memberikan pre-test kepada peserta pelatihan. Pre-test yang diberikan bertujuan untuk mengetahui kondisi kemampuan awal peserta pelatihan dan analisis kebutuhan peserta pelatihan. Kegiatan dilanjutkan dengan melakukan presentasi pembuatan media pembelajaran interaktif berbasis videoscribe dalam pembelajaran fisika. Selain presentasi, kegiatan diisi dengan diskusi dan praktik membuat media pembelajaran interaktif berbasis videoscribe. 


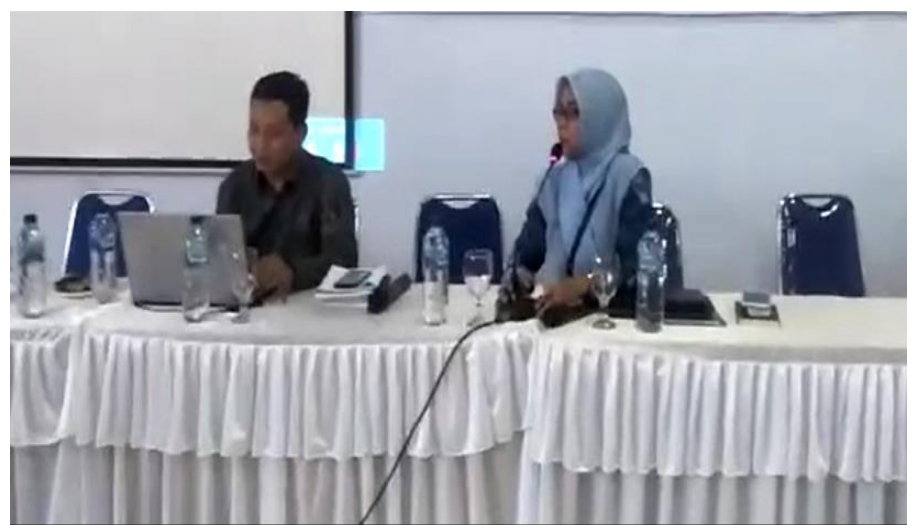

Gambar 2. Kegiatan pemaparan materi tentang media pembelajaran berbasis videoscribe

Tahap terakhir adalah tahap evaluasi. Pada tahap evaluasi tim juga menganalisis kegiatan selama pelatihan. Pada tahap ini tim datang ke sekolah pada tanggal 23 Januari 2020 untuk melihat hasil media pembelajaran yang sudah dibuat oleh guru, serta memonitoring penggunaan videoscribe dalam pembelajarn fisika. Hasil monitoring dijadikan sebagai bahan evaluasi untuk kegiatan-kegiatan yang akan dilaksanakan selanjutnya.

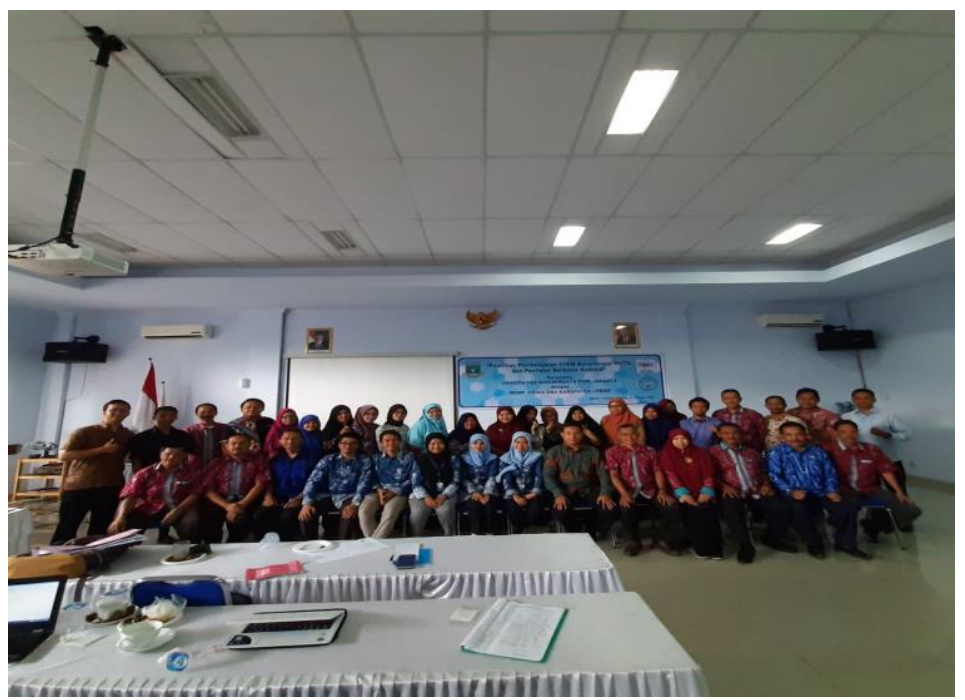

Gambar 3. Tim Abdimas dan Peserta Pelatihan

Pembuatan media pembelajaran berbasis ICT, yaitu sparkol videoscribe merupakan salah satu keterampilan guru dalam menggunakan teknologi (Amin, 2019). Pembelajaran dengan menggunakan teknologi sangat berperan dalam upaya meningkatkan kualitas pendidikan (Umbara, Rosyid, \& Setiawan, 2019). Guru sebagai tenaga pendidik harus melakukan inovasi dalam pembelajaran (Murniawaty \& Nuryana, 2018). Guru harus mampu memperbaharui kompetensi dan pengetahuannya dalam bidang teknologi informasi di era revolusi 4.0 (Munir, 2009).

Gunawan (2015) menjelaskan bahwa, multimedia terdiri dari berbagai jenis media untuk menyampaikan pesan/informasi kepada pengguna sesuai tujuan dan fungsinya. 
Terdapat beberapa komponen utama multimedia yang dirangkai dalam format digital yang disusun sedemikian rupa sehingga menarik dan memotivasi pengguna untuk belajar. Komponen-komponen tersebut adalah teks, gambar, audio, video, dan animasi. Satu komponen lagi bisa ditambahkan yaitu interaktif, sehingga multimedia bisa disebut sebagai media pembelajaran interaktif. Zacharia (2003) menegaskan bahwa, penggunaan media pembelajaran interaktif dapat lebih meningkatkan kemampuan inferensi logika dan kemampuan menarik kesimpulan.

Pembuatan videoscribe yang merupakan salah satu solusi dalam pengembangan pembelajaran interaktif fisika yang memberikan ide baru untuk para guru dan merupakan salah satu penerapan teknologi masa kini. Videoscribe merupakan aplikasi yang mudah dipelajari dengan fitur yang sudah ada didalamnya. Program aplikasi yang dapat dipergunakan dalam membuat presentasi video, dengan animasi tangan bergerak pada sebuah papan atau white board (Suryani, Zubaidah \& Yusron, 2018). Animasi tangan ini dapat seirama dengan objek berupa teks atau gambar yang ditampilkan pada layar, sehingga tampilannya seperti tangan sipembuat sendiri.keunikan lainnya terletak pada penjelasan suatu topik media gambar dan tulisan yang ditulis atau digambar.

Fitur dalam videosribe memiliki ribuan gambar yang dapat dipilih, sehingga memudahkan kita untuk memberikan tampilah yang menarik. Backsound juga dapat ditambahkan dari sparkol ataupun dapat memilih sendiri music yang akan dipakai. Pengaturan waktu dapat diatur sesuai dengan kebutuhan materi yang akan ditampilkan. Videoscribe dapat dipublikasikan dalam jenis file mp4, wav, dan dapat langsung membagikan pada jejaring sosial seperti facebook, youtube dan sho.com.

Pembuatan videoscribe mudah untuk dibuat dengan berbagai macam tampilan fitur, sehingga dapat memudahkan untuk membuatnya. Guru fisika di Lebak sangat antusias dalam mengikuti pengabdian masyarakat ini. Adanya pelatihan videoscribe dapat meningkatkan kemampuan guru dalam pemanfaatan teknologi saat ini. Sejalan dengan Amin (2019) menjelaskan bahwa kegiatan pengabdian berupa workshop pembuatan media pembelajaran dengan sparkol videoscribe ini memberikan kontribusi kepada guru, baik itu perubahan pada tingkat kepahaman mengenai pembuatan media sparkol videoscribe, maupun pada paradigma berpikir dan sangat memotivasi para guru untuk mengembangkan media pembelajaran berbasis ICT yang menarik. Pemanfaatan videoscribe ini diharapkan dapat meningkatkan minat belajar fisika siswa di Kabupeten Lebak, sehingga dapat memperbaiki nilai hasil belajar fisika siswa. Siswa juga dapat menunduh langsung videoscribe yang telah dibuat guru melalui jejaring sosial. Video ini juga dapat meminimalisir jam kosong yang ada di sekolah, saat guru tidak dapat datang mengajar karena keprluan dinas siswa dapat belajar sendiri melalui videosribe.

Kegiatan pengabdian kepada masyarakat di MGMP Fisika Kabupaten Lebak berjalan dengan baik sesuai dengan hasil kuisioner umpan balik tingkat kepuasan mitra dalam pelaksanaan pengabdian kepada masyarakat yang mengatakan bahwa mitra menanggapi respon positif (95\%) dengan kegiatan pengabdian ini. Kegiatan ini menambah keterampilan guru dalam membuat media pembelajaran yang interaktif dan inovatif dalam mempersiapkan bahan ajar di sekolah. 


\section{SIMPULAN}

Kegiatan pengabdian kepada masyarakat di MGMP Fisika Kabupaten Lebak berjalan dengan baik sesuai dengan hasil kuisioner umpan balik tingkat kepuasan mitra dalam pelaksanaan pengabdian kepada masyarakat yang mengatakan bahwa mitra menanggapi respon positif (95\%) dengan kegiatan pengabdian ini. Kegiatan ini menambah keterampilan guru dalam membuat media pembelajaran yang interaktif dan inovatif dalam mempersiapkan bahan ajar di sekolah. Media pembelajaran berbasis videoscribe merupakan salah satu inovasi terbaru bagi guru-guru di MGMP Fisika Kabupaten Lebak.

Saran guru agar kegiatan ini dapat berjalan terus dengan berbagai jenis pengabdian lainnya. Guru berharap selalu ada inovasi terbaru untuk meningkatkan kegiatan pembelajaran fisika di sekolahan sehingga dapat meningkatkan kemampuan guru dan juga meningkatkan prestasi belajar siswa.

\section{Ucapan Terima Kasih}

Penulis mengucapkan terima kasih kepada: Lembaga Penelitian dan Pengabdian Kepada Masyarakat Universitas Indraprasta PGRI yang telah membantu dan memfasilitasi dana pada hibah pelaksanaan kegiatan abdimas dan MGMP Fisika Kabupaten Lebak, Banten yang bersedia menjadi mitra dalam pelaksanaan kegiatan abdimas ini.

\section{REFERENSI}

Amin, S. (2019). Peningkatan profesionalisme guru melalui pelatihan pengembangan media pembelajaran sparkol videoscribe di Kabupaten Malang. Jurnal Pengabdian Pada Masyarakat, 4(4), 563-572.

Arsyad, A. (2009). Media pembelajaran. Jakarta: Rajawali Pers.

Dasmo, Astuti, I. A. D., \& Sumarni, R. A. (2017). Pengembangan media pembelajaran interaktif berbasis lectora inspire dalam pembelajaran fisika. In Prosiding Seminar Nasional PGRI 2017 (pp. 168-173).

Ena, O. T. (2001). Membuat media pembelajaran interaktif menggunakan piranti lunak presentasi. Yogyakarta: Indonesia Language and Culture Intensive Course Universitas Sanata Dharma.

Gunawan. (2015). Model pembelajaran berbasis ICT. Mataram: FKIP Unram Press.

Isman, A., Yaratan, H., \& Caner, H. (2007). How technology is integrated into science education in a developing country: North Cyprus case. Turkish Online Journal of Educational Technology-TOJET, 6(3), 54-60.

Octavianingrum, D. (2016). Pengembangan media audio visual sparkol videoscribe dalam pembelajaran mengelola pertemuan/rapat di lembaga pendidikan profesi (LPP) IPMI Kusuma Bangsa Surakarta jurusan administrasi perkantoran. Skripsi. Surakarta: Universitas Sebelas Maret. 
Pariartha, I. G. M. A., Parmiti, D. P., \& Sudatha, I. G. W. (2013). Pengembangan media pembelajaran berbasis multimedia interaktif pada mata pelajaran IPA untuk siswa kelas VIII Semester 1 di SMP Negeri 3 Singaraja tahun pelajaran 2012/2013. Jurnal Edutech Undiksha, 1(2), 51-60.

Rahmawati, F., Soegimin, W. W., \& Kardi, S. (2016). Pengembangan perangkat pembelajaran fisika model inkuiri terbimbing berbantuan videoscribe pada materi kalor untuk meningkatkan hasil belajar siswa SMAN 1 Kedungwaru. JPPS (Jurnal Penelitian Pendidikan Sains), 5(2), 1039-1047.

Sparkol. (2014). VideoScribe for education. Retrieved September 2, 2019 from www.videoscribe.co/education-apply

Suryani, P. D., Zubaidah, M. P., \& Yusron Wikarya, M. P. (2018). Pengaruh penggunaan media sparkol videoscribe terhadap hasil belajar siswa pada pembelajaran seni rupa di SMP Negeri 4 Padang. Serupa The Journal of Art Education, 7(1), 1-16.

Winastiti, D. D., Kurniawan, E. S., \& Maftukhin, A. (2012). Peningkatan motivasi belajar fisika melalui pemanfaatan media pembelajaran animasi yang diproduksi Pustekkom pada siswa kelas VIII SMP Setya Budi Purworejo tahun pelajaran 2011/2012. Radiasi: Jurnal Berkala Pendidikan Fisika, 1(1), 28-33.

Zacharia, Z., \& Anderson, O. R. (2003). The effects of an interactive computer-based simulation prior to performing a laboratory inquiry-based experiment on students' conceptual understanding of physics. American Journal of Physics, 71(6), 618-629.

\section{Copyright and License}

This is an open access article distributed under the terms of the Creative Commons Attribution 4.0 International License, which permits unrestricted use, distribution, and reproduction in any medium, provided the original work is properly cited. (C) 2020 Indica Yona Okyranida, Irnin Agustina Dwi Astuti. 